\title{
FOOD PROVISIONING, PREY COMPOSITION, AND NESTING SUCCESS OF OSPREYS IN NORTHWESTERN CALIFORNIA
}

MICHAEL ACADEMIA, Humboldt State University, One Harpst Street, Arcata, California 95521; mha23@humboldt.edu

The Osprey (Pandion haliaetus), with a nearly worldwide breeding distribution and a tolerance for both fresh and salt water, feeds almost exclusively (99+\%) on fish (Grove et al. 2009). The availability of prey is an important factor influencing its productivity (Van Daele and Van Daele 1982, Harmata et al. 2007). Time spent on foraging is a function of prey availability, and success in breeding may be related to food provisioning (Dykstra 1995) as well as the food supply (Croxall et al. 1988). Under favorable conditions, provisioning rates are elevated, and birds fully meet their own energetic requirements and those of their chicks (Cairns 1987, Weimerskirch 1998). Proximate causes of nest failure include bad weather, avian and nonavian competitors, and predation, as well as insufficient care by inexperienced parents. If the weather is bad, the adults may be unable to forage (Hudson 1985). However, the ultimate cause of nest failure may often be food shortage (Steenhof and Newton 2007); for example, a female unable to provision her chicks abandons her brood, which is then vulnerable to predation.

Identification of prey is a foundational element of animal ecology (Errington 1935), and, for raptors, the types of prey and their distribution can affect population shifts (Newton 1979). Hence an understanding of diet is fundamental for the successful management and conservation of these birds (Giovanni et al. 2007). Here I report on the composition of the prey of Ospreys nesting along the coast of northwestern California and measure the relationship between nesting success and food-provisioning rates.

From 15 May through 15 August 2018, I spent145.63 hours observing six nests along the coast of Humboldt and Del Norte counties (to quantify rates of provisioning and fledging; Figure 1) and 119.75 hours at the mouth of the Klamath River (to observe foraging). Ospreys were observed by means of a Barska 30-90 × 90 Waterproof Colorado Spotter spotting scope and Wingspan Optics Nature Pro HD $8 \times 42$ binoculars. I used a Panasonic Lumix DMC-FZ300K digital camera to photograph prey. With the assistance of Andrew Kinziger of Humboldt State University's Fisheries Program, I identified each fish to the lowest taxonomic level possible (at least to family).

I defined successful foraging as a male Osprey returning to the nest with prey and successful provisioning as delivery of that prey to the female and chicks. Other behaviors noted included failed attempts at foraging, defense against predators, territorial defense, perching, preening, resting, nest refurbishment, incubating, and abandonment (neither adult present).

I calculated nest success and productivity by the method of Steenhof and Newton (2007). Nest success is the proportion of nesting pairs that raise young to the age of fledging, on the basis of well-grown offspring observed in the nest at some point before fledging. I divided the number of successful nests by the total number of active nests observed. Productivity is calculated per territorial pair as the number of young produced that reach the minimum age acceptable for assessing success (Steenhof and Newton 2007). Therefore, I divided the number of fledglings by the total number of active nests observed.

I compared the time allocated to provisioning and other activities between successful and failed nests, and calculated the standard deviation of this difference. With RStudio 3.5.2, I used a Pearson's chi-squared analysis with Yate's continuity contingent to determine if there was a significant difference between provisioning of successful versus failed nests. 


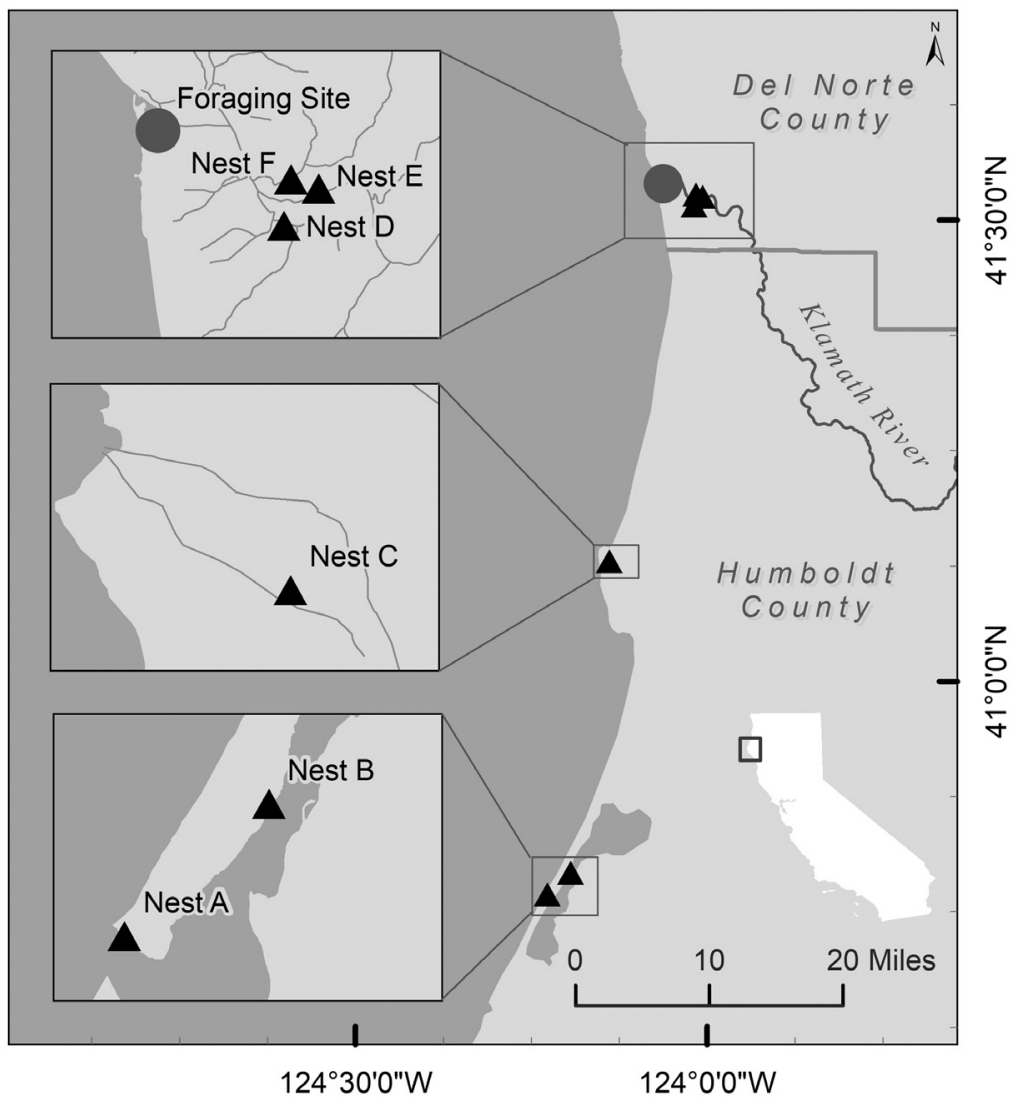

Figure 1. Location of the six Osprey nests monitored and the mouth of the Klamath River, site of observations of Osprey foraging, in Humboldt and Del Norte counties, northwestern California.

Table 1 Prey of Ospreys Observed in Humboldt and Del Norte Counties, California

\begin{tabular}{lcc}
\hline Prey species & $\begin{array}{c}\text { Number of } \\
\text { prey items }\end{array}$ & Percent of total \\
\hline American shad, Alosa sapidissima & 105 & 20.4 \\
Jacksmelt, Atherinopsis californiensis & 19 & 3.7 \\
Pacific lamprey, Entosphenus tridentatus & 50 & 9.7 \\
Salmon and trout, Salmonidae & 130 & 25.3 \\
Sculpins, Cottoidea & 7 & 1.4 \\
Smelt, Osmeridae & 35 & 6.8 \\
Starry flounder, Platichthys stellatus & 4 & 0.8 \\
Surfperch, Embiotocidae & 52 & 10.1 \\
Unknown & 112 & 21.8 \\
Total & 514 & \\
\hline
\end{tabular}




\section{NOTES}

Table 2 Time Spent in Provisioning and Other Activities by Ospreys Monitored in Humboldt and Del Norte Counties, California

\begin{tabular}{lccc}
\hline & \multicolumn{3}{c}{ Activity (minutes) } \\
\cline { 2 - 4 } Breeding status & Provisioning $^{a}$ & Other $^{b}$ & Total \\
\hline Successful & 3756 & 2258 & 6014 \\
Failed & 618 & 2465 & 3083 \\
Total & 4374 & 4723 & 9097 \\
\hline
\end{tabular}

aSuccessful foraging and prey consumption by adults and young.

${ }^{b}$ Failed attempts at foraging, perching, preening, resting, defense, incubating, nest refurbishing, and abandonment (neither adult present).

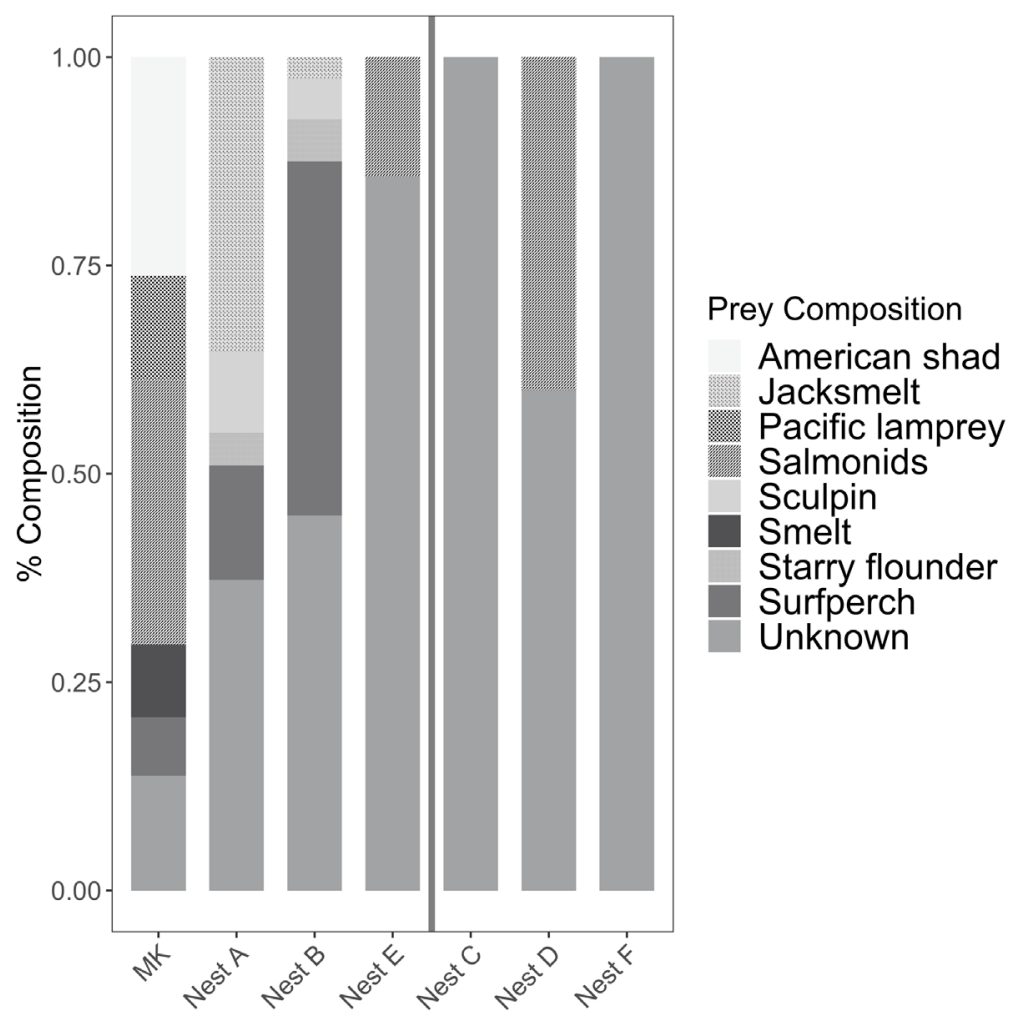

Figure 2. Percent composition of the prey of Ospreys foraging at the mouth of the Klamath River (MK) and brought to six nests in Humboldt and Del Norte counties, California. Nest A fledged two young, nest B three, and nest E one. Nests C, D, and F failed. 


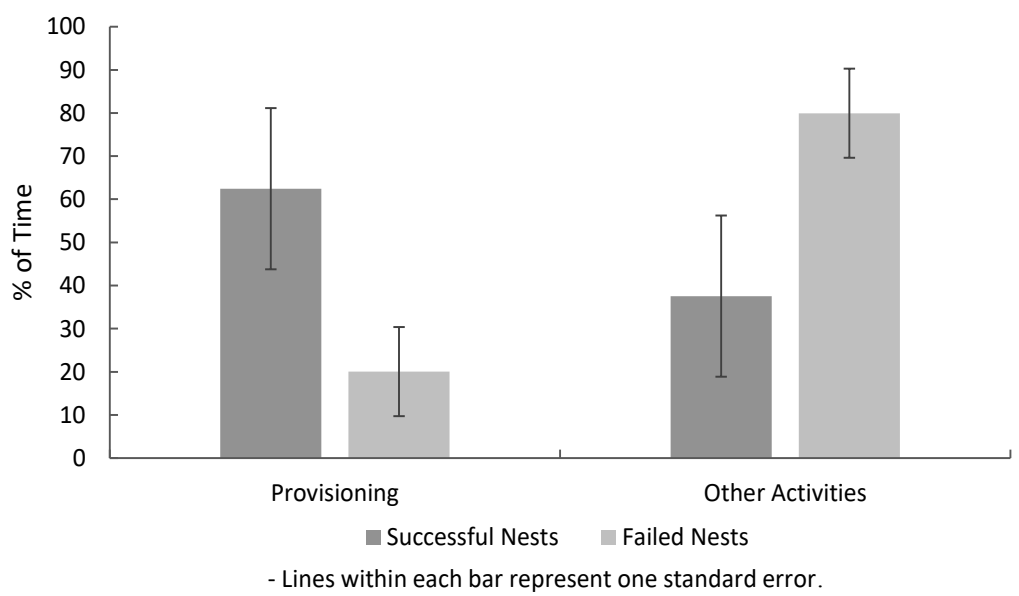

Figure 3. Percentage of time that Ospreys devoted to provisioning and to other activities at three successful nests $(S D=18.7)$ and three failed nests $(S D=10.3)$. Lines within each bar represent one standard error.

The identified prey consisted primarily of the non-native American shad (Alosa sapidissima), salmon and trout (Salmonidae), Pacific lamprey (Entosphenus tridentatus), surfperch (Embiotocidae), and jacksmelt (Atherinopsis californiensis; Table 1, Figure 2). The time spent provisioning was greater at successful nests than at failed nests $\left(\chi^{2}=1466.7, \mathrm{df}=1, p<0.001\right.$; Table 2, Figure 3$)$. Three of the six nests fledged young (50\% nesting success), and productivity was 0.83 young per active nest.

At successful nests, Ospreys spent more time on successful food provisioning, while those at failed nests spent more time on other activities, such as defense against predators, perching, and preening (Figure 4). According to Pearson's chi-squared test, the difference was strongly significant, suggesting that a nest's success is associated with greater success in foraging and higher rates of provisioning $(p<0.001$; Table 2). For maintenance of a stable Osprey population, long-term productivity must average 0.95-1.30 young per active nest (Henny and Wight 1969, Henny 1977), so the pairs I monitored may have had a poor year in 2018, in spite of the Osprey's recent trend of vigorous population increase (Sauer et al. 2017).

In evaluating the expansion of forage fisheries, managers may use data on prey composition. My study may inform ecosystem-based fisheries management, a holistic management approach that considers trophic interactions (NMFS 2016). In the Klamath River, the proliferation of a dominant prey species, the non-native American shad, introduced from 1871 to 1881 , could have implications for native salmonids. It is uncertain if the shad is a harmful invasive species or a benign introduction (Hasselman et al. 2012), as interactions between it and native salmonids have not been studied (Brown and Sax 2007).

Special thanks to Darren Ward, Andre Buccheister, Jose Marin Jarrin, Andrew Kinziger, and Desiree Early of Green Diamond Corporation, who granted me access to private property, to Kenneth Burton and Chet Ogen for nest locations, to Melissa Collin for the study area map, to Max Blasdel for the prey-composition figures, and to Benjamin P. Skillman for the RStudio analysis. Thanks to Daniel Cooper, Ryan Terrill, and an anonymous reviewer for improvements to the initial version. 
NOTES

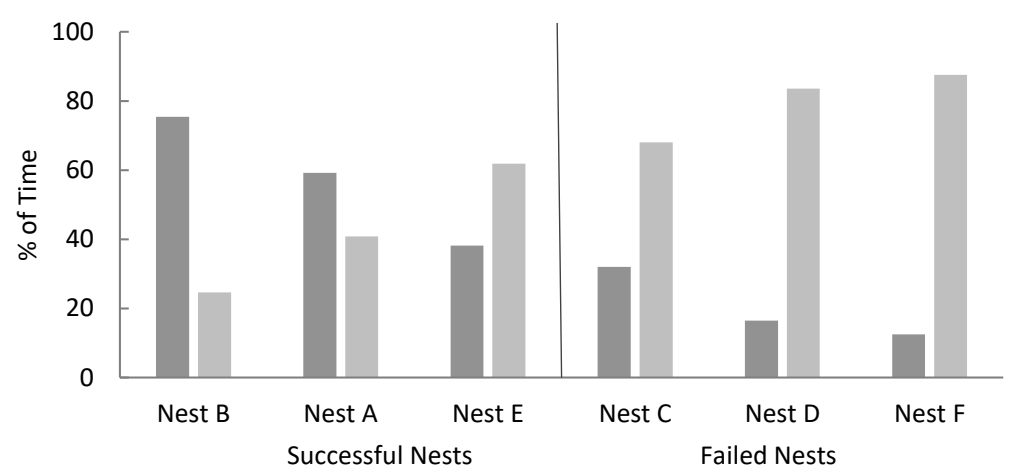

arovisioning $\quad$ Other Activities

Figure 4. Percentage of time Ospreys devoted to provisioning and to other activities at the six nests monitored in Humboldt and Del Norte counties, California. Nest B fledged three young, nest A two, and nest E one. Nests C, D, and F failed.

\section{LITERATURE CITED}

Brown, J. H, and Sax, D. F. 2007. Does biological invasion decrease biodiversity? Cons. Mag. 8(2):16-17.

Cairns, D. K. 1987. Seabirds as indicators of marine food supplies. Biol. Oceanogr. 5:261-271.

Croxall, J. P., McCann, T. S., Prince, P. A., and Rothery, P. 1988. Reproductive performance of seabirds and seals at South Georgia and Signy Island, South Orkney Islands, 1976-1987: Implications for Southern Ocean monitoring studies, in Antarctic Ocean Resource Variability (D. Sahrhage, ed.), pp. 261-296. Springer-Verlag, Berlin; doi 10.1007/978-3-642-73724-4_23.

Dykstra, G. I. R. 1995. Effects of contaminants, food availability, and weather on the reproductive rate of Lake Superior Bald Eagles (Haliaeetus leucocephalus). Ph.D. dissertation, Univ. of Wis., Madison.

Errington, P. L. 1935. The significance of food habits research in wild life management. Science 81:378-379; doi 10.1126/science.81.2103.378.

Giovanni, M. D, Boal, C. W., and Whitlaw, H. A. 2007. Prey use and provisioning rates of breeding Ferruginous and Swainson's hawks on the southern Great Plains, USA. Wilson J. Ornithol. 119:558-569; doi 10.1676/06-118.1.

Grove, R. A., Henny, C. J., and Kaiser, J. L. 2009. Osprey: Worldwide sentinel for assessing and monitoring environmental contamination in rivers, lakes, reservoirs, and estuaries. J. Toxicol. Env. Health B 12:15-44; doi 10.1080/10937400802545078.

Harmata, P. J., Restani, M., and Harmata, A. R. 2007. Settlement patterns, foraging behavior, and reproductive success of Ospreys along a heterogeneous river corridor. Can. J. Zoology 85:56-62; doi 10.1139/z06-190.

Hasselman, D. J., Hinrichsen, R. A., Shields, B. A., and Ebbesmeyer, C. C. 2012. American shad of the Pacific Coast: A harmful invasive species or a benign introduction? Fisheries 37:115-122; doi 10.1080/03632415.2012.659941.

Henny, C. J. 1977. Research, management, and state of the Osprey in North America, in World Conference on Birds of Prey, Vienna, 1-3 October 1975 (R. D. Chancellor, ed.), pp. 199-222. Int. Council Bird Preserv., London. 


\section{NOTES}

Henny, C. J., and Wight, H. M. 1969. An endangered Osprey population: Estimates of mortality and production. Auk 86:188-198; doi 10.2307/4083495.

Hudson, P. J. 1985. Population parameters for the Atlantic Alcidae, in The Atlantic Alcidae (D. N. Nettleship and T. R. Birkhead, eds.), pp. 233-261. Academic Press, London.

Newton, I. 1979. Population Ecology of Raptors. Buteo Books, Vermillion, SD.

NMFS (National Marine Fisheries Service) 2016. Ecosystem-based fisheries management policy of the National Marine Fisheries Service National Oceanic and Atmospheric Administration. NMFS Policy 01-120; www.fisheries.noaa.gov/ resource/document/ecosystem-based-fisheries-management-policy.

Sauer, J. R., Niven, D. K., Hines, J. E., Ziolkowski, D. J. Jr., Pardieck, K. L., Fallon, J. E., and Link, W. A. 2017. The North American Breeding Bird Survey, results and analysis 1966-2015, version 2.07.2017. Patuxent Wildlife Research Center, Laurel, MD; www.mbr-pwrc.usgs.gov/bbs/bbs.html.

Steenhof, K., and Newton, I. 2007. Assessing raptor nest success and productivity, in Raptor Research and Management Techniques (D. M. Bird and K. L. Bildstein, eds,), pp. 193-220. Hancock House, Surrey, BC, Canada.

Van Daele, L. J., and Van Daele, H. A. 1982. Factors affecting the productivity of Ospreys nesting in west-central Idaho. Condor 84:292-299; doi $10.2307 / 1367371$.

Weimerskirch, H. 1998. How can a pelagic seabird provision its chick when relying on a distant food resource? Cyclic attendance at the colony, foraging decision and body condition in Sooty Shearwaters. J. Anim. Ecol. 67:99-109; doi 10.1046/j.1365-2656.1998.00180.x.

Accepted 22 April 2019

\section{BOOK REVIEWS}

Field Guide to Bird Sounds of Western North America, by Nathan Pieplow. 2019. Houghton Mifflin Harcourt. 633 pp. Many drawings, photos, figures, spectrograms. Recordings and spectrograms of all the sounds also available as supplemental material at www.petersonbirdsounds.com. Paperback, \$28.00. ISBN 978-0-547-90557-0.

Like many of you, I have bookshelves overflowing with all sorts of bird books- to the point where I have adopted a personal policy of buying a new one only if it replaces one I have, or if it represents a unique contribution. When Nathan Pieplow's earlier eastern version of this guide appeared, there was no question that it met the second requirement. That book sits within arm's reach of my desk. Living in the West, however, I have been eagerly awaiting the completion of the set with the publication of a western version.

Pieplow has created the first comprehensive publication covering the sounds made by North America's birds. But that does not represent his most valuable contribution. That lies in the introductory material. In those sections he gives us a systematic way to listen to bird sounds, to describe them, to remember them, and to communicate with others about them. Most of us distinguish the trilled songs of the Chipping Sparrow and Dark-eyed Junco by the junco's song having a ringing, more musical quality than the somewhat mechanical sound of the chippie. But Pieplow shows us what those subjective descriptions mean in objective, visible terms. That sort of information can be applied to a variety of comparisons of similar songs and calls. He gives us five basic and easily remembered ways to describe a single note's pitch pattern. This not only makes it easier to recognize notes, it allows us to explain to others what to listen 